\title{
My best Geographer's Dress: Bodies, Emotions and Care in Early-career Academia
}

This is the accepted version of an article which is published in in Geografiska Annaler: Series B, Human Geography. DOI: https://doi.org/10.1080/04353684.2019.1568200

To cite this article: Federica Bono, Valerie De Craene \& Anneleen Kenis (2019): My best geographer's dress: bodies, emotions and care in early-career academia, Geografiska Annaler: Series B, Human Geography, DOI: 10.1080/04353684.2019.1568200.

Federica Bono*

Old Dominion University

Department of Political Science and Geography

Norfolk, Virginia, United States

fbono@odu.edu

Valerie De Craene* (corresponding author)

University of Leuven

Division of Geography and Tourism

Celestijnenlaan 200E, 3001 Leuven, Belgium

valerie.decraene@kuleuven.be

Anneleen Kenis*

King's College London and Research Foundation - Flanders (FWO)

Department of Geography

London, WC2R 2LS

United Kingdom

anneleen.kenis@kcl.ac.uk

\footnotetext{
*These authors contributed equally to this work.
} 


\title{
My best Geographer's Dress: Bodies, Emotions and Care in Early-career Academia
}

\begin{abstract}
In this paper, we draw on our personal experiences with the perpetuating gender bias in (early-career) academia, more specifically within geography. We develop two main arguments. First, we argue that everyday academic practices stand in sharp contrast with the critical content geography, as a discipline, aims to study and teach - including its feminist, anti-colonial, and queer understandings. Strikingly, geography as a field does not seem able to apply its academic insights into its internal organisation. Indeed, everyday academic practices within geography reproduce structural gendered inequalities. Consequently, geography reproduces the historical 'maleness' of the discipline, both in terms of who embodies it and through the methods and topics it focuses on. Second, we reflect on the strategies we develop to denounce and alter the unjust practices we are confronted with. Yet, these strategies reveal the double bind early career women face, as these very strategies may risk to undermine one's own precarious position, or to give the skewed impression of reproducing the male, disembodied ideal we are fighting.
\end{abstract}

Keywords: Geography, Gender, Emotions, Embodiedness, International Mobility, Early-career Academia 


\section{Introduction}

Social science research has shown the perpetuating gender bias within (and beyond) academia. These studies reveal a consistent and continuing range of gender biases at each stage of the hiring, tenure, and promotion process as well as in peer review and teaching evaluations (for an overview, see Savonick and Davidson 2017). Both general academic and discipline-specific trends can be identified.

The historical 'maleness' of geography as a discipline, which becomes clear in introductory or overview books (see also Nayak and Jeffrey 2011; McDowell 1992), received growing attention since 1979, when Linda McDowell showed that geography departments were mainly occupied by male faculty, thanks to the unpaid and invisible labour by their spouses (p. 153). She also revealed that there were very few articles about or written by women. Almost four decades since McDowell's critique, recruitment for faculty positions in (geography) departments is still gendered (Herschberg et. al. 2014). The gender imbalance is not only paramount in the number but also in the type of positions that male versus female academics obtain ${ }^{1}$. Women tend to end up on short-term contracts, with less favourable contractual conditions, or with a higher teaching load (Theall and Franklin 2001).

Geography's historical masculine legacy is not only exemplified in who embodies it (men), but also by the topics on which it focuses (Nayak and Jeffrey 2011). As we will show in this paper, topics like sexuality or emotions tend to be devalued in geographical research, precisely because of their assumed association with a more 'female' approach.

In this paper, we draw on our personal experiences to highlight the perpetuating gender bias in earlycareer academia. Following Harding (1991) and Rose (1997) we believe that there is no neutral place from where to conduct research. It is therefore crucial to reveal, at least partly, our own positionality. We are three early-career women in geography in three different geographical contexts. Our research interests and experiences are varied, from political ecology and political economy to gender and sexuality research. Among the three of us, we share research and teaching experiences ranging from large universities to small colleges in Belgium, the Netherlands, the United Kingdom, Sweden, and the United States.

Our experiences as early career women in geography intersect with other identities. Rather than attempting to limit our experiences to our gendered identities, we emphasise the intersectionality of gender, nationality, ethnicity, sexuality, (dis)ability, and age.

The fact that we do not have long-term faculty positions significantly affects the gender biases we experience. When writing this article we also realised that our early-career status implies additional challenges and risks. At several stages during the writing process we wondered how to bring up issues without consequences at a later stage. Sharing experiences is crucial for improving women's position in academia. Yet, doing so might have the inadverted consequence of (further) undermining precisely that position. Therefore, we pondered between adopting a more intimate writing style, revealing personal feelings and details, or embracing the more typical 'detached' academic role which looks at processes from an artificial distance. This struggle resulted in the not-entirely-satisfying choice of slightly anonymising our experiences. We decided to provide sufficient context to make sense of the specific case without revealing details that would easily trace the case back to a particular person or 
situation. We also decided to use the pronoun 'we', regardless of whether we had all experienced what we are writing about or whether it was only one of us.

However, we not only reflected on our rather precarious positions, but also on the mere fact we were concerned with it. Indeed, privilege - male, senior or otherwise - not only implies that fewer barriers have to be overcome. Paradoxically, it also seems to open up the possibility of communicating emotions and self-criticism without taking professional risks. We watched senior male professors admit their nervousness to teach a large-sized classroom or to teach in English without any problem. These statements did not seem to undermine their credibility - as we saw happening after similar interventions from female, junior instructors - rather, this seemed to make them more sympathetic with students and staff.

Because the purpose of this paper is to expose particular gender differences and biases in building an academic career in geography, we start from the terms 'men' and 'women', while being aware of the problematic nature of these concepts and knowing that many people self-identify as non-binary, genderqueer or otherwise. We use these concepts only to refer to socially identified groups amongst whom particular statistically relevant patterns can be observed. We do not intend to suggest that everyone would identify with either one of these categories, nor that these are the only forms of gender-related discrimination that exist. Furthermore, this choice can give the skewed impression of heteronormativity even if this is not the message we want to give, neither the assumption or experience from which we start.

We also struggled with the fact that it is extremely difficult, maybe even impossible, to attribute an individual experience to gender bias. Gender bias can mostly only be deduced from its systematic character. By including in this paper only cases that triggered our common experience and/or were recognised as significant by other female colleagues, we tried to move beyond idiosyncratic experiences, even if these experiences in themselves reveal a lot of what is at stake. Thereby we intend to reveal the structures and power relations behind our everyday experiences. In other words, we see the themes emerging from our narratives not as universal, but ubiquitous.

In what follows, we examine a series of everyday academic practices that are often presented as gender neutral, and confront these with insights from feminist, anti-colonialist, and queer geographical scholarship. Specifically, we zoom in on our own experiences with requirements on international mobility (section 2), teaching and care work (section 3 ), the idea(l) of knowledge production as rational and objective (section 4), and the presumption of the neoliberal scholar as disembodied and disembedded (section 5). These experiences do not only reveal the difficulties geography has to put its own critical theorisations into practice, but also the double bind early career women face when contesting structural (gendered) inequalities.

\section{The Geography of Women}

To apply for a faculty position, research funding, or - ironically - travel grants, search committees and review boards increasingly expect a long research stay abroad on the candidate's CV (Herschberg et. 
al. 2014). While both fieldwork and (visiting) scholarships in principle meet this requirement, there exists a tendency to not consider fieldwork abroad as sufficient. Moreover, a geographical division sneaks in in terms of where you have to go. The idea(I) is a PhD, post-doc or position in the AngloSaxon countries, while candidates should have conducted fieldwork in the Global South (Herschberg 2017; Daigle 2018). Committee members thus prefer candidates who combine the 'expertise' of having worked at another research institution in the Western world with the 'real life experience' of having lived and conducted research in the 'unknown and often difficult conditions' in the Global South. This resembles the historic romanticised image of the travelling geographer studying the remotest areas of the world. It is telling that in one of the geography departments we have been working, the time teaching assistants spend assisting on field trips is only to a very limited extend acknowledged towards their doctoral program. As the head of the department in question noted, 'after all, geographers like to go on field trips abroad'.

These imaginaries of geographical field trips and stays abroad do not only have (neo)colonial implications, the self-evidence that a geographer likes and must go abroad is also relevant from a gender perspective. In what follows, we deal with the constraints that female embodiedness and gendered divisions of labour pose for going abroad. As early career women, the most important caring task we are personally confronted with which has implications for going abroad, is the care for young children. Importantly, there are large gender differences on this terrain. Studies show that the international mobility of men increases after they have children, while that of women decreases (Storme 2014, Herschberg et. al. 2014). This is not surprising. Conversations with colleagues and friends revealed that many women do not consider it an all too big burden if their (male) partner leaves for a few weeks or even more. They perform the majority of household and child caring tasks anyway. Conversely, if women plan to go abroad without taking the children with them, this is often considered far from obvious by male partners. In the case they do so anyway, they have to 'compensate' for this later, thus restricting their academic progress at a later stage in their lives. Related to this, studies show that even when there are no children involved, women are more inclined than men to accompany their partners abroad, often giving up their own career (Tharenou 2008).

Though a topic we have been concerned with for longer, we first-handedly experienced the consequences when we were not awarded an important research grant because we did not have a 'Iong stay abroad'. The rejection was especially remarkable because our proposal and profile were classified as excellent. When another grant opportunity became available, we did not see many options other than looking for the 'easiest' way to go abroad to bolster our application-mindful of rather superficially performing an act which was required from us, instead of doing something that would sincerely improve our academic research at that stage. The fact that we were subsequently awarded with the grant confirmed the problem. We were happy, but concerned that we had implicitly substantiated the idea that going abroad is possible regardless of social relations and caring responsibilities. This could make it even more difficult for other academics to claim that such requirements completely ignore the social (caring) networks in which people are embedded and that complicate going abroad.

Both taking children abroad and leaving them with a partner or other carer 'at home', is far from evident. The challenge of leaving children at home does not only relate to practical and organisational reasons. There is also an important emotional factor. Psychological studies show that children under six years are too young to cope well with the absence of their primary caregiver, still mostly women 
(Kelly and Lamb 2003). This is something mothers are intuitively well aware of and it definitely does not facilitate their 'choice' to travel for an extended period.

Taking children with you is equally challenging. Considerations range from practical and financial issues, such as finding suitable and affordable accommodation and childcare, to being solely responsible for daily caring tasks, and coping with difficulties of the children to adapt to the new situation. In our experience, the lack of social networks abroad is most challenging. Unexpected school closures, for example, leaves us with no other option but to take our children with us to field interviews or to the lecture hall. Moreover, the situation negates the aims of going abroad. Spending weeks through the administrative procedures of obtaining a place at school or in a nursery, making long commuting distances as the best places are no longer available, and having to be at home early in the evening, restricts exactly those activities (networking or otherwise) that are interesting for a scholar abroad.

Instead of accommodating for these challenges, funding requirements sometimes just bring more constraints. One of our research projects included six months at a foreign institution. However, our travel grant only allowed for three separate two-month periods, as this would presumably benefit the research goals. Practically, this implied finding suitable accommodation, a place at school and childcare every single time. Just the fact that it takes three weeks to apply for a place at school in our host country and that you can only do so once you are physically there, made it practically impossible. As a result, we did not see an option other than going for six consecutive months, even if that was largely on our own expenses.

This relates to our more general experiences of how the pressure to be internationally mobile can lead to emotionally strenuous and financially precarious situations. Over the course of our short careers, we have invested a lot of personal money or accepted precarious teaching positions abroad without health insurance or a sufficient salary to even pay the rent, making us highly dependent on savings and others for our daily lives ${ }^{2}$. International and institutional mobility, in combination with short term contracts, also prevents building up social and legal rights, such as health insurance credentials, maternity allowances or retirement benefits.

When communicating all of these issues to the highest levels of the university, the vice-rector of research agitatedly answered: 'Gaining foreign experience is an element that is important for all researchers, women or men [...] As a female scientist, you want to be judged by your scientific qualities and not by your gender, don't you ? $^{\prime 3}$. Here, a (liberal form of) equality feminism is (mis) used to conceal the much more structural way gender relations are at play. As Acker and Armenti (2004, p. 19) note, 'typically, and ironically, a meritocratic discourse incorporates gender-blindness in the name of fairness'.

Thus, the dominant approach to international mobility starts from a disembodied and disembedded masculine individual, detached from social place-based relations and extremely mobile across space and time (Mellor 1996, 1997, 2006). These ideas contradict contemporary ways of thinking within (and beyond) geography that emphasise the importance of spatial and temporal context and fluidity (see e.g. Skeggs e.a. 2004). Instead of approaching academics as free floating atoms who can be taken out of a particular social environment and put somewhere else without any constraints, geographic scholarship increasingly emphasises how everyday spaces, including academic spaces, are produced through embodied social practices (Browne e.a. 2007). 


\section{Educating Geography}

When it comes to teaching, the focus on international mobility becomes very particular. Teaching as a scholar from abroad confronts early career women with the triple bias of gender, age, and being a foreigner. The discussion of a gender bias in higher education is not new and has particularly been researched in teaching evaluations (Baker and Copp 1997; Andersen and Miller 1997; Basow and Silberg 1987; Basow 1995; Wagner, Rieger, and Voorvelt 2016). These studies show how the automatic assumption in Western patriarchal culture that men 'have legitimate authority, while women must prove their expertise to earn the same level of respect' (MacNell, Driscoll, and Hunt 2014, p. 293) reverberates through the way students evaluate female academics. Students give higher ratings to research that is thought to be done by men (Goldberg 1968; Paludi and Strayer 1985), judge hypothetical male candidates for a faculty position as more qualified (Burns-Glover, Veith, 1995), and misattribute male instructors' education upward and female instructors' education downward (Miller and Chamberlin 2000). These studies remain conclusive even when controlling for different classroom settings, teaching styles, materials, and student results on examinations (see e.g. MacNell e.a. 2014, Mengel e.a. 2017). Moreover, both Bennett (1982) and Mengel et al. (2017) show that early-career women or women who students perceive as less experienced, are less likely to be accepted as an authority and receive lower ratings on student evaluations.

Similarly, we observed that students more easily ascribed our male colleagues a kind of 'natural' authority, while we had to 'prove' our own authority or even felt questioned or undermined at certain moments. For example, senior students protested the fact that they were not allowed to work on an exam longer than one class period, although the maximum duration of the exam was the same for every class and established as a university policy. We could expect from first-year students not to be aware of the policy, but not from upper level students, who have been at the university for several years.

We also experienced how our gendered identity intersected with being a scholar from abroad. For example, when discussing the oil-production of the United States a student loudly interrupted us and antagonistically proclaimed that '[the student's] country is not a big oil-producing country' and what the instructor was saying was all false. Similarly, in another class, each time we discussed something related to our host country, a student started to heavily shake her head, roll with her eyes, and sigh loudly. In a classroom setting with less than 20 students, this was overtly disrupting. From these and other experiences, as well as from conversations with native male colleagues teaching the same courses, it became clear that the students were not always accepting that a foreign instructor discussed facts or processes about 'their' country". Negative comments on our course evaluations focused on the fact that the instructor was foreign ('her accent's, 'she is not used to the education system here') and junior (the 'lack of experience'). A senior professor, chair of another department, who had observed and positively evaluated two of our classes, said that in her experience, students seemed to be 'particularly hard' for junior and foreign professors.

Thus, our experiences as instructors in geography sharply contrast the content that we teach and are especially relevant for the field of geography. There are good reasons to assume that geography students find it enriching to be taught by academics from all over the world, and that academic institutions would encourage this experience. Similarly, we could assume that students who are taught 
to think critically about hegemonic discourses (race, gender, class, etc), made conscious of the colonial legacy of their discipline and the world at large, and initiated in anti-colonial ways of thinking, would be more open towards lecturers who do not exemplify the stereotypes of authority. Surprisingly, our experiences suggest that these theoretical understandings only partly filter through to daily academic practices.

Our experiences affected our self-confidence, attitude, and time investment. We started to spend more time preparing classes, as we searched for 'domestic' videos and other sources to add to the learning materials to claim the authority of our argument. Having to 'prove' our legitimacy led to stress, which impacted our well-being and physical health. When we consequently had to cancel one of our classes, this affected us not only financially, but also put our academic career at risk. Additionally, we noticed how we started to perform differently in class. For example, we started to increasingly pay attention to our clothing and tried to come across more professionally. Yet, students also regularly expressed they 'liked our dress' and in an e-mail-conversation about a class-related issue, one student wrote: 'btw [sic] I would like to say that I like your fashion sense! I notice it everyday in class, it's extremely nice [clapping hands emoji]'. Needless to say, these comments made us feel exposed, and a little too obvious that students were focusing on our appearance rather than on what we aimed to teach them. This strategy does not come in a vacuum. On a Facebook post discussing gender bias in student evaluations, several female instructors commented how dressing differently can help to increase your authority. Interestingly, one commenter wrote how a male colleague had advised her to 'dress less feminine, to be taken more seriously'. These kinds of examples show both the relevance and duplicity of clothing.

While clothing was maybe the most visible way in which we tried to adapt, other strategies were at least as important. Most noteworthy, we tried to be 'softer' in our approach to the students and in our ways of addressing them. We started to spend more time giving detailed feedback and especially paid attention to include sufficient positive and encouraging feedback. Our availability via office hours increased, we started to invest more time in personal assistance, and we became more lenient towards late submissions or test make ups. Interestingly, comments in our course evaluations started to focus less on our (perceived lack of) teaching or academic expertise but more on caring related aspects of our teaching. Students commanded our 'good heart' and our 'kindness'.

Female academics not only need to perform better in order to be granted a similar amount of credibility and authority as their male colleagues, they are also judged differently. Studies show how women are more expected to engage in academic care work, not only by students, but also by their peers (El-Alayli e.a. 2018). Consequently, women spend disproportionally more time on 'emotional labour' (Hochschild 1983). When they fail to meet these stereotypical expectations of 'warmth' or 'personal assistance', women are evaluated more negatively than men (Bennett 1982). Conversely, female instructors are rewarded when they are more 'nurturing' towards students (Bennett 1982; Centra and Gaubatz 2000). Consequently, we sometimes felt confronted with a double bind. We had to appear less feminine to be attributed authority, while we simultaneously had to meet particular gender stereotypes to be appreciated more generally.

Of course an increased attention for care is not, in itself, negative. Building on a feminist ethics of care (Federici 2012, Ahmed 2014, Mountz e.a. 2015), we consider academic care work as important and necessary. The increase in mental health concerns in academia underscores this importance as 
research recommends academic institutions, including faculty, to treat mental health issues more as part of their responsibility (Kitzrow, 2003; Levecque e.a. 2017). We experienced the positive sides of our approach as we were able to solve problems within and outside the classroom setting because of a broader knowledge of students' personal lives and an enhanced relation of trust with them.

At the same time, academic care work is intensive and time-consuming, while often remaining invisible and therefore not validated. Moreover, as long as women (need to) take up a disproportionate part of emotional labour within higher education, gender stereotypes of women being 'more nurturing' and 'caring' are confirmed rather than reversed.

Acknowledging and recognising these gender biases is therefore important as they significantly affect women's academic career paths in three ways. First, teaching evaluations increasingly gain in importance when hiring new faculty members and when evaluating junior faculty members for tenure (Boring 2017; MacNell, Driscoll, and Hunt 2014; Mengel, Sauermann, and Zölitz 2017). Second, early career women invest considerably more time into formal and informal aspects of teaching (Bennett 1982; Acker and Armenti 2004; Boring 2017). This is particularly relevant given the fact that junior academics are already heavily burdened with juggling their time between courses, research, service, grant writing (Wagner, Rieger, and Voorvelt 2016), and caring tasks outside academia. Finally, the gender gap in teaching evaluations may have an influence on the self-confidence of junior women scholars, leading to a higher dropout of academia (Mengel, Sauermann, and Zölitz 2017).

\section{Space for Emotions?}

The gender(ed) biases early-career women in geography face do not only relate to teaching and their own geographies, but also to the topics they are supposed to focus on. Traditionally, men have dominated the pure and applied natural sciences (Knights and Richards 2003) - disciplines that are often discursively referred to as 'hard' sciences - as opposed to so-called 'soft' sciences, like social sciences or humanities. At many institutions, geography as well still tends to be considered as a 'hard' science (by geographers and non-geographers) because of the historical linkages between physics and physical geography (Massey 1999) ${ }^{6}$. This seems to be especially the case in those departments that combine physical and social geography within one geography program. Still, also more generally, a binary between soft-female and hard-male sciences seems to be present. This binary echoes in notions of what constitutes good research and therefore a good researcher. It starts from the idea(I) of science as detached, objective, and rational. This is all 'valued' as masculine to the detriment of engagement, subjectivity, passion, and desire, which have been devalued and feminised (Anderson and Smith 2001). Harding (1986, p. 63) argues that 'the cultural stereotype of science as tough, rigorous, rational, impersonal, competitive and unemotional has continued to be inextricably intertwined with issues of men's gender identities in a mutually reinforcing manner'.

Methods, topics, and scholars that do not comply with the dominant idea(I) of detachment, objectivity, and rationality are often met with a greater scepticism. While geographers have been studying a variety of topics, researchers studying the spatiality of emotions, sexualities or other so-called 'soft' topics seem to be perceived as less of a 'real' geographer (De Craene 2017a). We had to repeatedly argue why our research was relevant within a geography department and why we would not study a more 'serious' topic, such as gentrification, erosion or urban development. When one of our colleagues 
wanted to use emotional geographies as a lens through which to study migration, her (male) supervisor strongly discouraged her to do so, wondering what the point was of studying emotions as they are so elusive. This scepticism sometimes seems to extrapolate to the validity of related research methods, teaching, and student activities. When Bachelor students suggested a lecture on the geography of prostitution to be taught for their parents during an open-day, the department chair denied this suggestion. He claimed this had to be a joke by the students and added that this topic is not the core of what our geography training aims to teach [and] this is not the image of geography we want the parents to take home'.

The discursive binary between 'hard' and 'soft' sciences, topics, and methods, leads to horizontal segregation, with a clustering of women in the 'softer' sciences or working on 'soft' topics or methods (Knights and Richards 2013). Anderson and Smith (2001, p. 7) explain how the gendered basis of knowledge production is probably a key reason why emotions have long been banished from social science and most other critical commentary: 'Thinking emotionally is implicitly cast as a source of subjectivity which clouds vision and impairs judgement, while good scholarship depends on keeping one's own emotions under control and others' under wraps.' Indeed, regardless of the topic or methods, expressing (specific) emotions remains problematic too. When one of our colleagues shared her uncertainties about how to proceed with her research project, her male supervisor replied: 'Don't start acting like the archetypical female insecure doctoral researcher'.

Following Anderson and Smith (2001), we argue that a suppression of emotions produces an incomplete understanding of the world. Neglecting emotions excludes a key set of relations through which lives are lived and societies are made (see also Davidson e.a. 2005; De Craene 2017a). Therefore, in our work it has been important to take up these often-neglected domains of human positioning in the world. Yet, when we designed a research methods class using the geographies of sexuality as a research topic, we read the following comment in the student evaluations: 'I don't understand why we are carrying out research on sexuality while there are so many real and important topics in the world, such as the refugee crisis or climate change. It is clear that we work on this topic only because the professor and the teaching assistant think this is a fun topic. The teaching assistant is very enthusiastic about the topic and clearly has a personal passion for it, but I don't understand why this is part of our geography training.' The student not only questions the societal relevance of studying sexualities, they also question the academic relevance for including sexualities as part of a geography curriculum. By (solely) referring to feelings ('passion', 'enthusiastic'), rather than, for example, our academic curiosity, rigour, and expertise, the student emphasises that they 'understand' why we (teaching assistants at that time) have chosen this topic to be part of the curriculum, while simultaneously not considering these reasons as legitimate or sufficient to make it relevant for a geography training, reaffirming dominant ideas of the objective and detached researcher. Moreover, by referring to our 'personal' passion, the student attaches this choice to our personal lives and identities, rather than to our professional lives as researchers. We are not disputing, let alone problematising, the presence of 'personal' reasons to be committed to a particular topic. The point is that our colleagues working on housing, financial geographies or air pollution, did not receive similar comments, while there are potentially as many personal motivations at stake. 


\section{Embodied Geographies}

The cultural stereotype of science as tough, rigorous, rational, impersonal, competitive, and objective not only obscures the emotional aspects of science, but also promotes a disembodied way of 'doing' science. The researcher's body as an instrument of research is excluded (Crang 2003; Longhurst e.a. 2008). It often seems as if the role of the researcher remains to 'overcome the immediacy of people's corporeal experiences by acts of will and intellect' (Anderson and Smith 2001, p. 9), neglecting 'our warm, fleshy bodies and material practices' (Gorman-Murray 2017).

While there is a growing attention for the embodiment of research, research subjects, and researchers, including within geography (Longhurst and Johnston 2014; De Craene 2017b), this does not seem to seep through to everyday geographic academic practice. Especially in relation to fieldwork, scholars have pointed on the prevailing masculine understanding of geographers as fully able-bodied (see e.g. Nairn 1999; Anderson 2001; Jokinen and Caretta 2016). Using their own fieldwork experiences, Jokinen and Caretta (2016, p. 1674) show how 'the idealisation of a geographer's body in effect normalises all bodies as machine-like entities that are expected to participate in any kind of field activities'. Consequently, the body - whether ill, skinny, aging, pregnant, changing, tired, depressed, impaired, fat, stressed, etc. - is excluded, or only accepted when passing as able-bodied (Hansen and Philo 2007).

This idealisation becomes most clear in relation to geographical fieldwork, but is as important in everyday academic practices. This goes from daily expectations, such as always being on time, to more fundamental confrontations with human embodiedness such as illness, pregnancy or aging. For example: when teaching a class outside of campus, a majority of the students as well as the instructor arrived late the few times that the only train connection was delayed or cancelled. Yet, on the teaching evaluations, rather than blaming the train connection that impacted more than half of the students taking the class, students blamed the instructor for not being on time. In other occasions as well, we noticed how students seem to assume that an instructor can, or should, move beyond place and time and not be constrained by the practical material embedding in life. This corresponds to what Mary Mellor $(1996,1997,2006)$ describes as the patriarchal, neoliberal idea(I) of 'men' as always fit, healthy, fed, and rested. Not only are these imaginary male agents detached from caring and other social relations, they are also detached from place and time.

This idea(I) fundamentally affects the life of (early-career female) scholars. A bodily situation many early career women confront and which radically breaks with these assumptions is of course pregnancy. Though this is a well-known issue and one of the few feminist concerns which made it into actual legislation, discrimination on the workfloor is still omnipresent and this does not seem to be different for academia (Equality and Human Rights Commission, 2018). For instance, we were 'strongly encouraged' not to accept a fellowship after we informed the department chair we were pregnant. This pressure ranged from 'friendly' suggestions - that it would be better for ourselves to withdraw our candidacy as we would not be able to make the most out of it anyway-to more direct confrontations that it would harm the 'student experience' and thereby also the university. When we answered that it could also be an important learning experience for the students as it increases the 'normality of doing things differently' (Hansen and Philo 2007, p. 493), this was laughed away. Human embodiedness might have become a well-researched area of study, it is still perceived as a threat for the daily functioning of the neoliberal university (see also Longhurst 1995, 2001; Longhurst and Johnson 2014). Again, this example shows how even within geography departments where the 
subjective, the emotional, and the embodied have become central to the curriculum, these elements are not translated to the everyday academic practice of teaching.

The pressure not to accept the fellowship made us angry, and eager to show we could do it regardless. Soon, though, we were again confronted with a double bind on several levels. On the one hand, we wanted to fight the prejudice of pregnant women as weak, emotional, and not performing well. On the other hand, we had to be aware of not reproducing the disembodied ideal we were fighting. We wanted to resist the pressure to give up this position, but this became more difficult once confronted with less favourable conditions. After we had announced our pregnancy, our teaching load intensified and our proposed salary decreased. While obviously unlawful, it was difficult to prove these changes were due to the pregnancy and therefore discriminating.

\section{Conclusion}

Though each of these sections brings a story of its own, they also have much in common. First, we find that our experiences are especially striking for a discipline like geography, which aims to study and teach a critical understanding of the world order. Based on our experiences, it appears that, as a discipline, we do not seem to be able to apply these insights on the way we organise internally. We value Western institutions higher than others and we have biases towards instructors from abroad. Not only has geography erased women from its history, gender biases threaten to keep 'erasing' women and other less-privileged groups from geographical academia today. It does this not only through biased selection and evaluation procedures, but also by self-positioning itself as mainly 'hard' and 'objective' science. Subsequently, the ideal of research as detached, objective, and rational reproduces the ideal of a disembodied and disembedded researcher, who is not constrained by bodily restrictions and time-consuming caring tasks.

Second, we realised that our individual strategies to cope with these biases sometimes risk to internalise and even reinforce them. We made significant financial, emotional, health, and work-life sacrifices. We were eager to present ourselves as capable of dealing with these challenges, and did not always (sufficiently) stand up for our rights in order not to undermine already precarious positions. But, we also experienced that even small interventions created real change. Students started to adopt more critical viewpoints about their own country and about gender relations. Our choice for less 'typical' geographical research topics opened up the possibility for colleagues and students to make similar choices. We were positively surprised to see that in one class more than half of the students selected a gender-related dissertation topic even if this was something we had only dealt with in a minor way.

Still, we are especially confronted with the limitations of adopting individual strategies for change. While resisting and reacting to structural (gendered) inequalities within academia, we notice how our choices might sometimes reproduce exactly those biases we contest, and/or reproduce the detached neoliberal male ideal we are contesting. Therefore, we can only conclude that we need more transformative structural and institutional change. Instead of putting on our 'best geographer's dress" and try to fit in, we need to change the requirements in which to fit in. We need to confront daily 
academic practices with the critical legacy geography is rightly proud of and open up university spaces to those bodies that are now excluded. We have to transform what we teach into a living experience, recognising that learning also happens through daily practices. Only then, we can move to an academia that takes bodies, emotions, and care, seriously. Geography has mapped the theoretical contours of such an endeavour, it is now time to put these insights into academic practice.

\section{Acknowledgements}

We would like to thank Ruth Wauters for her constructive input and feedback in the early stages of this paper and Xhoana Ahmeti for her time and effort in proofreading our text. 


\section{Endnotes}

1. The gender action plan at KU Leuven, Belgium, states that $38,16 \%$ of assistant professors and $25,93 \%$ of full professors are women. Despite the 'equal opportunities policy' and a gradual increase in positions held by women (between $5 \%$ and $13 \%$ depending on departmental differences), the absolute number of positions beyond postdoctoral level still disproportionately go to men. (KU Leuven, Gender Action Plan 2014-2017).

2. We are conscious about our privileged position in this regard, and how such requirements are even more problematic for those without similar savings or support networks.

3. In the same email conversation, we also asked to make public the number of postdoctoral mandates which were awarded to respectively men and women. The vice-rector commented that ' $[\mathrm{M}]$ ore postdoctoral mandates have been awarded to men, but this is because there were more applications by men.' The fact that there was a significant disparity in the amount of applications by men versus those by women was not questioned.

4. Divya Tolia-Kelly (2017, p 326) shares a similar story in her account of the everyday experiences of black female academics within geography. She exemplifies how students challenged the authority of the black female instructor in a class on the myth of race by googling for evidence while being in the lecture theatre.

5. As Divya Tolia-Kelly (2017) notes, also the 'ethnicity' of accent is often a source for discrimination and criticism. She sharply shows that white Irish, Australian, Canadian, and Scottish accents are not received in the same way, pointing to the intersections of ethnic accents and race.

6. This is for instance the case in many universities in European countries, e.g. in Belgium, the Netherlands and France.

7. We hereby allude to Esther Newton's work "My best informant's dress" (1993).

\section{References}

Acker, Sandra, and Carmen Armenti. 2004. "Sleepless in Academia". Gender and Education 16 (1): 324.

Ahmed, Sara. 2014. Selfcare as Warfare. http://feministkilljoys.com/2014/08/25/selfcare-as-warfare/ Accessed 25 January 2018.

Andersen, Kristi, and Elizabeth D Miller. 1997. "Gender and Student Evaluations of Teaching." PS:

Political Science \& Politics 30 (2). Cambridge University Press: 216-19.

doi:10.1017/S1049096500043407.

Anderson, Carolyn Anne. 2001. "Claiming Disability in the Field of Geography: Access,

Recognition and Integration." Social and Cultural Geography 2 (1): 87-93.

Anderson, Kay, and Susan J. Smith. 2001. "Emotional geographies." Transactions of the Institute of British geographers 26 (1): 7-10.

Baker, Phyllis, and Martha Copp. 1997. "Gender Matters Most: the Interaction of Gendered Expectations, Feminist Course Content, and Pregnancy in Student Course Evaluations." Teaching Sociology 25 (1): 29. doi:10.2307/1319109.

Basow, Susan A. 1995. "Student Evaluations of College Professors: When Gender Matters." Journal of Educational Psychology 87 (4): 656-65. doi:10.1037/0022-0663.87.4.656.

Basow, Susan A, and Nancy T Silberg. 1987. "Student Evaluations of College Professors: Are Female and Male Professors Rated Differently?" Journal of Educational Psychology 79 (3): 308-14. 
doi:10.1037/0022-0663.79.3.308.

Bennett, Sheila K. 1982. "Student Perceptions of and Expectations for Male and Female Instructors:

Evidence Relating to the Question of Gender Bias in Teaching Evaluation." Journal of Educational Psychology 74 (2): 170-79. doi:10.1037//0022-0663.74.2.170.

Boring, Anne. 2017. "Gender Biases in Student Evaluations of Teaching." Journal of Public Economics 145 (January): 27-41. doi:10.1016/j.jpubeco.2016.11.006.

Browne, Kath, Lim, Jason and Gavin Brown. 2007. Geographies of Sexualities: Theory, Practices and Politics. Ashgate, Surrey.

Burns-Glover, Alyson L., Dale J. Veith, 1995. 1995. "Revisiting Gender and Teaching Evaluations: Sex

Still Makes a Difference." Journal of Social Behavior and Personality 10 (1): 69-80.

Centra, John A, and Noreen B Gaubatz. 2000. "Is There Gender Bias in Student Evaluations of

Teaching?." The Journal of Higher Education 71 (1): 17-33. doi:10.1080/00221546.2000.11780814.

Crang, Mike. 2003. “Qualitative Methods: Touchy, Feely, Look-see?” Progress in Human Geography 27, pp. 494-504.

Daigle, Christine. 2018. "The Value of where you Earned your PhD". UniversityAffairs. November 20, https://www.universityaffairs.ca/opinion/in-my-opinion/the-value-of-where-you-earned-yourphd/.

Davidson, Joyce, Mr Mick Smith, and Liz Bondi, eds. 2012. Emotional geographies. Ashgate Publishing, Ltd.

De Craene, Valerie. 2017a. "Geographies of Sexualities: Bodies, Spatial Encounters and Emotions". Tijdschrift voor Economische en Sociale Geografie (Journal of Economic and Social Geography), 108 (3): 264-274.

De Craene, Valerie. 2017b. "Fucking Geographers! Or the Importance of Neglecting the Lusty Researcher's Body". Gender, Place and Culture, 24 (3), 449-464.

El-Alayli, Amani, Ashley A. Hansen-Brown, and Michelle Ceynar. 2018. "Dancing Backwards in High Heels: Female Professors Experience More Work Demands and Special Favor Requests, Particularly from Academically Entitled Students." Sex Roles 1-15.

Equality and Human Rights Commission. 2018. "Pregnancy and Maternity Discrimination Research Findings." https://www.equalityhumanrights.com/en/managing-pregnancy-and-maternityworkplace/pregnancy-and-maternity-discrimination-research-findings

Federici, Silvia. 2012. Revolution at Point Zero: Housework, Reproduction, and Feminist Struggle. Oakland, CA: PM Press.

Goldberg, Philip. 1968. “Are Women Prejudiced Against Women?.” Society 5 (5): 28-30. doi:10.1007/BF03180445.

Gorman-Murray, Andrew. 2017. "Embodied Emotions in the Geographies of Sexualities." Tijdschrift voor economische en sociale geografie 108 (3): 356-360.

Hansen, Nancy, and Chris Philo. 2007. "The Normality of Doing Things Differently: Bodies, Spaces and Disability." Tijdschrift voor Economische en Sociale Geografie 98 (4): 493-506.

Harding, Sandra. 1991. Whose Science? Whose knowledge? Cornell University Press, New York. Herschberg, Channah, Yvonne Benschop and Marieke van den Brink. 2014. "Gender Practices in the Construction of Excellence." GARCIA Working Papers, no 10. http://garciaproject.eu/wpcontent/uploads/2014/07/GARCIA working papers n.10.pdf

Herschberg, Channah. 2017. "Inequality practices in the construction of international mobility as a selection criterion for assistant professor positions." Paper presented at the International 
Women's Day Event, March 8th, University of Warwick, UK.

https://aminatwarwick.wordpress.com/2017/10/17/inequality-practices-in-the-construction-ofinternational-mobility-as-a-selection-criterion-for-assistant-professor-positions-by-channahherschberg/

Hochschild, Arlie Russell. 1983. The managed heart: commercialization of human feeling. Berkeley: University of California Press

Jokinen, Johanna, and Martina Angela Caretta. 2016. "When Bodies do not fit: an Analysis of Postgraduate Fieldwork". Gender, Place and Culture 23 (12): 1665-1676.

Kelly, Joan B., and Michael E. Lamb. 2003. "Developmental issues in relocation cases involving young children: When, whether, and how?." Journal of Family Psychology 17 (2): 193-205.

Kierstead, Diane, Patti D'Agostino, and Heidi Dill. 1988. "Sex Role Stereotyping of College Professors: Bias in Students' Ratings of Instructors." Journal of Educational Psychology 80 (3): 342-44. doi:10.1037//0022-0663.80.3.342.

Kitzrow, Martha Anne. 2003. The Mental Health Needs of Today's College Students: Challenges and Recommendations, NASPA Journal (41)1: 167-181

Knights, David, and Wendy Richards. 2003. "Sex Discrimination in UK Academia." Gender, Work and Organization 10 (2): 213-238.

Lawson, Victoria. 2007. Geographies of Care and Responsibility. Annals of the Association of American Geographers 97 (1), 1-11.

Levecque, K., Anseel, F., De Beuckelaer, A., Van der Heyden and J., Gisle, L. 2017. "Work organization and mental health problems in PhD students." Research Policy 46: 868-879.

Longhurst, R. 1995. "Geography and the Body." Gender, Place and Culture 2 (1): 97-106.

Longhurst, R. 2001. Bodies. Abingdon: Routledge.

Longhurst, Robyn, Elsie Ho, and Lynda Johnston. 2008. "Using 'the body' as an 'instrument of research': kimch'i and pavlova." Area 40 (2): 208-217.

Longhurst, R., and L. Johnston. 2014. "Bodies, Gender, Place and Culture: 21 Years on." Gender, Place \& Culture 21 (3): 267-278.

MacNell, Lillian, Adam Driscoll, and Andrea N Hunt. 2014. "What's in a Name: Exposing Gender Bias in Student Ratings of Teaching." Innovative Higher Education 40 (4). Springer Netherlands: 291303. doi:10.1007/s10755-014-9313-4.

Massey, Doreen. 1999. "Space-time, 'science' and the relationship between physical geography and human geography." Transactions of the Institute of British Geographers 24 (3): 261-276.

McDowell, Linda. 1979. "Women in British Geography." Area 11: 151-154.

McDowell, Linda. 1992. "Towards an Understanding of the Gender Division of Urban Space." Environment and Planning D: Society and Space 1: 59-72.

Mengel, Friederike, Jan Sauermann, and Ulf Zölitz. 2017. "Gender Bias in Teaching Evaluations." IZA Institute for Labour Economics Discussion Paper Series, no.11000.

Mellor, Mary. 1997. "Women, nature and the social construction of 'economic man'." Ecological Economics 20 (2): 129-140.

Mellor, Mary. 1996. "The politics of women and nature: Affinity, contingency or material relation." Journal of Political Ideologies 1 (2): 147-164.

Mellor, Mary. 2006. "Ecofeminist political economy." International Journal of Green Economics 1 (1/2): 139-150.

Miller, JoAnn, and Marilyn Chamberlin. 2000. "Women Are Teachers, Men Are Professors: a Study of Student Perceptions." Teaching Sociology 28 (4): 283. 
Mountz, Alison, Bonds, Anne, Mansfield, Becky, Loyd, Jenna, Hyndman, Jennifer, Walton-Roberts, Margaret, Basu, Ranu, Whitson, Risa, Hawkins, Roberta, Hamilton, Trina, Curran, Winnifred. 2015. For slow scholarship: A feminist politics of resistance through collective action in the neoliberal university. ACME: An International Journal for Critical Geographies, 14(4), 1235-1259.

Nairn, Karen. 1999. "Embodied Fieldwork." Journal of Geography 98 (6): 272-282.

Nayak, Anoop, and Alex Jeffrey. 2011. Geographical Thought. An Introduction to Ideas in Human Geography. Pearson Education Limited, Harlow.

Newton, Esther. 1993. "My best informant's dress: The erotic equation in fieldwork." Cultural Anthropology 8 (1): 3-23.

Paludi, Michele A, and Lisa A Strayer. 1985. "What's in an Author's Name? Differential Evaluations of Performance as a Function of Author's Name." Sex Roles 12 (3-4): 353-61. doi:10.1007/BF00287601.

Rose, Gillian. 1997. "Situated Knowledges. Positionality, Reflexivities and Other Tactics." Progress in Human Geography 21 (3): 305-320.

Savonick, Danica, and Cathy Davidson. 2017. An annotated bibliography of important recent studies on gender bias in academe. https://www.hastac.org/blogs/superadmin/2015/01/26/genderbias-academe-annotated-bibliography-important-recent-studies Accessed 13 January 2018

Skeggs, B., Moran, L., Tyrer, P., and Binnie, J. 2004. "Queer as folk: Producing the real of urban space." Urban Studies, 41(9), 1839-1856.

Storme, Tom. 2014. "Exploring a Small World. Motivations and Obligations for Academic Travel in a Flemish Context." PhD diss., University of Ghent.

Tharenou, Phyllis. 2008. "Disruptive decisions to leave home: Gender and family differences in expatriation choices." Organizational Behavior and Human Decision Processes 105 (2): 183-200. https://doi.org/10.1016/j.obhdp.2007.08.004

Theall, Michael, and Jennifer Franklin. 2001. "Looking for Bias in All the Wrong Places: a Search for Truth or a Witch Hunt in Student Ratings of Instruction?." New Directions for Institutional Research 2001 (109): 45-56. doi:10.1002/ir.3.

Tolia-Kelly, Divya P. 2017. "A day in the life of a Geographer: 'lone', black, female." Area, 49 (3): 324328.

Wagner, Natascha, Matthias Rieger, and Katherine Voorvelt. 2016. "Gender, Ethnicity and Teaching Evaluations: Evidence From Mixed Teaching Teams." Economics of Education Review 54 (October): 79-94. doi:10.1016/j.econedurev.2016.06.004. 